\title{
Pseudoephedrine and acetaminophen relieved sinus symptoms in the course of the common cold
}

Sperber SJ, Turner RB, Sorrentino JV, et al. Effectiveness of pseudoephedrine plus acetaminophen for treatment of symptoms attributed to the paranasal sinuses associated with the common cold. Arch Fam Med 2000 Nov/Dec;9:979-85.

\section{QUESTION: In patients with a cold, is a combination of pseudoephedrine hydrochloride and acetaminophen (PHA) more effective than placebo in relieving sinus symptoms?}

\section{Design}

Randomised \{allocation concealed $*\} \dagger$, blinded (clinicians and patients),* placebo controlled trial.

Setting

3 university medical centres in the eastern US.

\section{Patients}

430 patients who were $18-65$ years of age (mean age 28 $y, 66 \%$ women), had cold symptoms of $\leqslant 48$ hours in duration, and reported sinus symptoms of at least moderate severity. Exclusion criteria were diastolic blood pressure $>90 \mathrm{~mm} \mathrm{Hg}$, underlying illness that might be affected by the study drugs, use of medication that might interact with the study drugs, pregnancy, or potential for pregnancy. 412 patients (96\%) completed the study.

\section{Intervention}

Patients were allocated to pseudoephedrine, $60 \mathrm{mg}$, and acetaminophen, $1000 \mathrm{mg}(\mathrm{n}=216)$, or identical placebo tablets $(\mathrm{n}=214)$. The drugs were given in 2 doses, 6 hours apart.

\section{Main outcome measures}

Change from baseline in overall sinus symptom assessment score and a composite score of weighted averages of sinus symptoms (sinus pressure, pain, and congestion) at 2 hours after the second dose. Assessments were made using a 5 point scale $(0=$ absent and $4=$ severe)

\section{Main results}

Analysis was by intention to treat. 2 hours after the second dose of medication, patients who received PHA had a greater decrease in overall sinus assessment score than did patients who received placebo $(\mathrm{p}<0.001)$ (table).

Pseudoephedrine and acetaminophen (PHA) v placebo for relieving sinus symptoms in the course of the common cold

\begin{tabular}{llll} 
& \multicolumn{2}{l}{ Mean decrease from baseline } & \\
\cline { 2 - 3 } $\begin{array}{c}\text { Outcomes at 2 hours } \\
\text { after the second dose }\end{array}$ & $\begin{array}{l}\text { PHA } \\
\text { (baseline) }\end{array}$ & $\begin{array}{l}\text { Placebo } \\
\text { (baseline) }\end{array}$ & $\begin{array}{l}\text { Difference } \\
(95 \% \mathrm{Cl})\end{array}$ \\
$\begin{array}{c}\text { Overall sinus symptom } \\
\text { assessment score }\end{array}$ & $1.30(2.5)$ & $0.93(2.6)$ & $0.37(0.20$ to 0.54$)$ \\
\hline $\begin{array}{c}\text { Weighted sinus } \\
\text { symptom score }\end{array}$ & $1.14(2.1)$ & $0.84(2.2)$ & $0.30(0.13$ to 0.47$)$ \\
\hline
\end{tabular}

$\ddagger$ Abbreviations defined in glossary; difference and $\mathrm{Cl}$ calculated from data in article.

Patients who received PHA also had a greater decrease in the sinus weighted score $(\mathrm{p}<0.001)$ (table). PHA recipients also had greater decreases than placebo recipients in sinus assessment score and sinus weighted score 2 hours after the first dose of medication $(\mathrm{p} \leqslant$ 0.04). Adverse effects were reported by more patients receiving PHA than by those receiving placebo $(p=0.04)$ and included nervousness, nausea, dizziness, dry mouth, and somnolence of mild or moderate severity, except for 2 patients with severe nausea in the PHA group.

\section{Conclusion}

In patients with cold and sinus symptoms, a combination of pseudoephedrine hydrochloride and acetaminophen relieved sinus symptoms within 2 hours of the second dose of medication.

*See glossary.

$\dagger$ Information provided by author.

\section{COMMENTARY}

The clinical significance of the trial by Sperber $e t$ al is in doubt for several reasons. Firstly, the patients were healthy adults rather than the children and unhealthy adults who most often present with the common cold. Secondly, the meaning of a reduction in the symptom score in relation to patient distress is uncertain. For instance, is a reduction from severe to moderately severe the same as a reduction from moderately severe to mild? The results are presented only in terms of score reductions. It would be more useful to know what proportion of patients benefited meaningfully. Thirdly, the benefits are small; reduction of symptoms of $36 \%$ by placebo is only improved to $51 \%$ by PHA.

Side effects assessed as being related to the drug occurred in $19 \%$ of patients receiving PHA compared with $11 \%$ of patients receiving placebo. The effects were severe in 2 patients and warranted stopping the drug in 2 others. The benefit risk ratio seems small.

PHA is a compound, and symptom relief may have come from either or both of its components. Because most of the adverse effects are attributed to pseudoephedrine, we do not know whether its inclusion is important in achieving the small benefits.

It is questionable whether the benefits outweigh the risks; therefore, I would not recommend the use of PHA in the patients described.

Charles Bridges-Webb, MBBS, MD University of Sydney Burwood, New South Wales, Australia 